\title{
N3b Stage Finding
}

National Cancer Institute

\section{Source}

National Cancer Institute. N3b Stage Finding. NCI Thesaurus. Code C48716.

A general term that refers to a TNM finding of cancer metastases in multiple lymph nodes. The definition of N3b TNM finding depends on the specific type of cancer that it refers to; for example, for breast cancer it refers to metastases in clinically detected ipsilateral internal mammary lymph nodes in the presence of one or more positive axillary lymph nodes, or in more than 3 axillary lymph nodes and in internal mammary lymph nodes with micrometastases or macrometastases detected by sentinel lymph node biopsy but not clinically detected; for gastric cancer it refers to metastases in sixteen or more regional lymph nodes; for nasopharyngeal cancer it refers to extension to the supraclavicular fossa. 